\title{
Peran Ibu Terhadap Kesiapan Anak Bersekolah
}

\author{
Santi Handayani \& Rena Latifa \\ Magister Sains Psikologi Pendidikan UIN Syarif Hidayatullah, Jakarta \\ santihandayani1310@gmail.com \\ rena.latifa@uinjkt.ac.id
}

\begin{abstract}
Children's school readiness includes ready school, ready family and ready children themselves. This research aims to observe whether a mother's support, mother-child attachment and demographic factor could affect an elementary grader's school readiness. The subjects in this research are 202 students' mothers. This research used purposive sampling and quantitative method. The validity of the instrument was tested by Confirmatory Factor Analysis (CFA). Meanwhile, the data was analyzed by using multiple regression analysis. The results of this research were shown that mother's support and gender together influence school readiness. Whereas the variable of mother-child's attachment, school entry age, working mother status, child's birth order were not statistically proven to be influential on school readiness.
\end{abstract}

Keywords: Mother support, mother-child attachment, children's school readiness

\begin{abstract}
Abstrak
Kesiapan bersekolah meliputi kesiapan lingkungan sekolah, kemampuan keluarga serta masyarakat untuk mendukung perkembangan anak secara optimal serta kesiapan individu anak. Penelitian ini bertujuan untuk melihat apakah dukungan ibu, kelekatan ibu dan anak serta faktor demografi secara bersama-sama memengaruhi kesiapan bersekolah anak Sekolah Dasar. Sampel dalam penelitian ini berjumlah 202 orang. Pengambilan sampel yang digunakan dalam penelitian ini menggunakan purposive sampling. Metode penelitian ini menggunakan kuantitatif. Validitas alat ukur dalam penelitian ini menggunakan Confirmatory Factor Analysis (CFA). Analisis data menggunakan multiple regression analysis (regresi berganda). Hasil penelitian menunjukkan bahwa dukungan ibu dan jenis kelamin anak mempengaruhi secara signifikan terhadap kesiapan bersekolah. Sedangkan kelekatan ibu-anak, usia masuk sekolah, status pekerjaan ibu serta urutan kelahiran anak tidak terbukti secara statistik berpengaruh terhadap kesiapan bersekolah anak.
\end{abstract}

Kata kunci: Dukungan ibu, ikatan ibu-anak, kesiapan sekolah anak-anak

\section{Pendahuluan}

Kesiapan bersekolah atau school readiness merupakan tonggak tumbuh kembang anak pada usia dini dimana tahap anak sudah siap untuk mengikuti perubahan/transisi kegiatan dari rumah ke sekolah (UNICEF, 2012). Kesiapan bersekolah bukan hanya kesiapan anak secara individu saja, melainkan juga kesiapan orang tua, kesiapan sekolah dan kesiapan lingkungan.

Janus dan Offord (2007) melakukan penelitian yang didasari adanya problem kognitif dan tingkah laku yang terjadi di SD selama bertahun-tahun. Penelitian lain telah membuktikan bahwa 
kesiapan bersekolah dan kesuksesan di masa yang akan datang tergantung tidak hanya pada kemampuan kognitif anak, tapi juga pada kesehatan mental dan fisik, kesejahteraan emosional dan kemampuan berhubungan dengan yang lain (Huffman, Mehlinger \& Kerivan, 2000). Duncan et al (2007) berfokus pada kesiapan bersekolah dan prestasi yang akan datang. Penelitian ini dilatarbelakangi oleh kebijakan pemerintahan George W Bush pada tahun 2002, yaitu kebijakan yang menanamkan program anak usia dini yang terampil secara akademis. Mereka meneliti bahwa pada hari pertama sekolah, anak perlu mengetahui angka dan huruf. Mereka harus mengetahui banyak kosakata yang akan mereka gunakan sebagai bekal untuk belajar dan negara dituntut untuk mendukungnya. Penelitian yang dilakukan Shala (2013) tentang perkembangan sosial emosional yang berpengaruh pada kesiapan bersekolah. Penelitian Shala ini dilatarbelakangi adanya tuntutan prasyarat masuk SD di Kosovo, yaitu kemampuan literasi dan matematika serta kematangan sosial.

Peneliti melakukan survey studi pendahuluan kepada guru SD terutama yang sedang atau pernah mengajar di kelas satu SD di sekolah Kharisma Bangsa, Tangerang Selatan. Studi pendahuluan tersebut dilakukan kepada 20 responden untuk melihat fenomena apa saja yang terjadi pada anak di awal semester kelas satu SD. Menurut responden studi pendahuluan, perlu dipersiapkan dikarenakan jika ini tidak dipenuhi atau anak dipaksakan untuk bersekolah padahal anak belum siap secara psikologis atau mental, maka anak akan mengalami kesulitan beradaptasi, tidak fokus, kurang mandiri, mengganggu guru atau teman di dalam kelas bahkan anak akan mogok sekolah.

Penelitian lain tentang pengaruh dukungan ibu terhadap kesiapan bersekolah telah banyak dilakukan, seperti yang dilakukan oleh Compton (2004) yang mengatakan bahwa dukungan ibu terhadap anak akan mendukung kesiapan bersekolah anak yang kemudian akan meningkatkan prestasi belajarnya. Connel dan Prinz (2002) menyatakan bahwa keluarga atau orang tua sangat berpengaruh terhadap kesiapan bersekolah anak. He Ye (2016) mengatakan bahwa kurangnya keterlibatan orang tua terhadap perkembangan anak akan berdampak pada kesiapan bersekolah dan seterusnya menyebabkan kurang berprestasinya anak di jenjang pendidikan selanjutnya.

Penelitian yang dilakukan oleh DeMulder, Denham, Schmidt dan Mitchell (2000) dilatarbelakangi akan banyaknya anak TK yang masih "menempel" dengan ibunya saat anak tersebut menjelang masuk SD. Mereka menemukan bahwa ada pengaruh positif antara kelekatan antara ibu dan anak terhadap kesuksesan akademis dan kesiapan bersekolah anak. Adanya kaitan antara kelekatan aman (secure attachment) dengan dimensi yang ada dalam kesiapan bersekolah seperti keterampilan matematika yang lebih baik (Dobbs et al, 2006), keterampilan pra-literasi dan keterampilan sosial (Van Ijzendoorn, Dijkstra \& Bus, 1995). Dimana sebaliknya, anak dengan kelekatan tidak aman (insecure attachment) mempunyai masalah interaksi sosial dan masalah tingkah laku yang berdampak pada hubungan anak dengan temannya dan guru di sekolah (DeKlyen et al, 1998). Selain itu kelekatan tidak aman juga berkaitan dengan penurunan nilai akademis (Jacobsen \& Hoffmann, 1997). 


\section{Kesiapan Bersekolah}

Pengertian kesiapan bersekolah, secara umum dapat dilihat pula pada kecukupan umur untuk masuk sekolah dan anak dapat berkembang dengan memuaskan, kesiapan bersekolah juga dapat dilihat dengan perkembangan pertumbuhan atau kematangan, contohnya jika ditinggal sendirian, anak melihatkan tanda bahwa dia telah siap untuk sekolah (Gredler, 1992). Berbeda pendapat dengan itu, Graue (1992) berpendapat bahwa kesiapan terletak pada anak dan lingkungannya.

Cross dan Power (2011) mengatakan bahwa definisi secara teori dari kesiapan bersekolah adalah kesiapan yang dapat mengidentifikasi keterampilan-keterampilan dasar, pengetahuan dasar, dan konsep yang dibutuhkan anak ketika mereka memasuki dunia sekolah agar dapat meraih prestasi di SD dan jenjang selanjutnya.

Menurut UNICEF (2012) pengertian kesiapan bersekolah anak mengandung dua macam karakteristik, yaitu transisi dan perolehan kompetensi. Disamping itu terdapat tiga dimensi, yaitu: ready children, berfokus pada pembelajaran dan perkembangan anak. Ready school, berfokus pada lingkungan sekolah tentang pembelajaran yang mendukung transisi anak yang perlahan menuju SD dan selanjutnya. Ready families, berfokus pada keluarga dan perilaku yang mendukung dan terlibat dalam pembelajaran dan perkembangan anak juga dalam masa transisi sekolah. Dengan kata lain adalah kesiapan anak untuk sekolah, kesiapan bersekolah untuk anak dan kesiapan keluarga dan komunitas untuk sekolah. Menurut UNICEF (2011), anak yang telah siap bersekolah adalah anak yang telah memiliki keterampilan-keterampilan dasar dan pengetahuan dalam beberapa bidang yang akan menunjang anak untuk sukses di sekolah. Dengan standar minimum ini menjadi batasan untuk anak agar mengetahui apa yang harus diketahui atau yang harus dilakukan, jadi mereka memasuki sekolah dengan siap dan semangat untuk belajar sehingga menjadi sebuah peralihan yang sukses menuju lingkungan sekolah dasar (Lara-Cinismo at al, 2004).

Dimensi dalam kesiapan bersekolah menurut Janus dan Offord (2007), adalah meliputi:

a. Physical health and well-being (kesejahteraan fisik) Cole (2006) berpendapat aktifitas yang dilakukan anak-anak dalam masa pertengahan sangat membutuhkan energi, stamina, kemampuan visual dan auditori serta motorik halus. Janus dan Offord (2007), yaitu anak sering masuk sekolah; anak siap secara fisik untuk beraktivitas di sekolah yaitu tidak kelelahan atau tidak kelaparan; anak bisa mengurus dirinya saat di toilet; anak dapat memegang pensil dengan benar; anak dapat naik turun tangga.

b. Language and cognitive development (perkembangan bahasa dan kognitif). Menurut teori Piaget, anak 6-7 tahun berada pada fase pra-operasional, dimana pencapaian utamanya adalah perolehan bahasa, berpikir secara simbolis, pemikiran dibatasi pada dominasi bentuk, persepsi dan pemahaman. Janus dan Offord (2007), yaitu anak dapat bercerita atau mengisahkan sebuah cerita; anak dapat mengutarakan keinginannya dengan jelas; anak mengerti apa yang disampaikan kepadanya; anak dapat mengucapkan kata dengan artikulasi yang jelas; anak tertarik pada kegiatan membaca; anak dapat membaca dan menulis kata yang sederhana.

c. Social competence (kompetensi sosial) mengacu pada kemampuan seseorang untuk bergaul dengan teman atau kelompoknya (Mildred Parten, 1932 di dalam Krause et al, 2010). Janus dan Offord (2007), yaitu anak bermain dan bekerja sama dengan teman sebayanya; anak dapat mengikuti aturan dan perintah (instruksi); anak menghormati barang orang lain; anak menghormati orang yang lebih tua; anak menerima tanggung jawab atas perbuatannya; tidak terlibat perkelahian fisik dengan orang lain. 
d. Emotional development menurut Janus dan Offord (2007), yaitu anak terlihat percaya diri; anak tidak menangis dan mengamuk; dapat menyelesaikan masalahnya sehari-hari; anak mengerjakan sesuatu sampai selesai; anak dapat duduk dengan tenang saat mengerjakan sesuatu; anak tidak mudah teralihkan perhatiannya; anak dapat menyesuaikan diri dengan lingkungan baru.

\section{Dukungan Ibu}

Definisi dukungan ibu dalam penelitian ini, akan menggunakan teori dari Epstein (2001), yaitu tentang dukungan orang tua, bagaimana mereka dapat secara aktif mendukung dan terlibat dalam kesiapan bersekolah dan prestasi belajar anak. Namun, penggunaan teori dukungan orang tua tersebut disesuaikan dengan tujuan dari penelitian ini, yaitu menjadi dukungan ibu karena disesuaikan dengan responden penelitian ini yaitu ibu dari anak SD kelas satu.

Dimensi dukungan ibu menurut Epstein (2001) yaitu:

a. Parenting, yaitu dimana keluarga atau orang tua membangun lingkungan yang dapat mendukung anak sebagai seorang murid.

b. Communicating, yaitu menjalin bentuk komunikasi yang efektif antara sekolah ke rumah dan rumah ke sekolah tentang program sekolah dan perkembangan anak.

c. Volunteering, yaitu bentuk dukungan ibu atau keluarga dalam acara sekolah.

d. Learning at home, dukungan ibu dalam membantu anak di rumah dalam membimbing anak mengerjakan pekerjaan rumah maupun tugas sekolah.

e. Decision making, yaitu dukungan ibu dalam mengambil keputusan dalam kepentingan sekolah.

f. Collaborating with the community, yaitu bentuk keterlibatan dalam komunitas sekolah.

\section{Kelekatan Antara Ibu dan Anak}

Teori kelekatan dikonsepkan oleh Bowlby (1988) yaitu menjelaskan tentang respon dari pengasuh terhadap kebutuhan-kebutuhan anak pada masa awal perkembangan anak yang akan memberikan hasil yang berbeda pada rasa aman saat kanak-kanak.

Dimensi dari kelekatan, yaitu: secure attachment, insecure anxious-ambivalent attachment dan insecure anxious-avoidant attachment (Ainsworth, 1978). Riset lainnya dilakukan oleh Main dan Solomon (1986). Dalam penelitian itu didapat dimensi lain dari kelekatan yaitu disorganized attachment (Chiccetti \& Carlson, 1989).

\section{Faktor Demografi}

Dimensi dalam faktor demografi dalam penelitian ini yaitu, usia masuk sekolah dasar; jenis kelamin anak; urutan kelahiran anak yang dibagi menjadi anak pertama, anak tengah, anak bungsu dan anak tunggal; status pekerjaan ibu, yaitu status ibu bekerja yang menghasilkan nafkah uang dan status ibu rumah tangga. 


\section{Hipotesis Penelitian}

Untuk melihat pengaruh yang signifikan dari dukungan ibu (parenting; communicating; volunteering; learning at home; decision making; collaborating with the community), kelekatan ibu dan anak (secure attachment, insecure anxious-ambivalent attachment, insecure anxiousavoidant attachment, disorganized attachment), faktor demografi (usia anak, jenis kelamin, urutan kelahiran, status pekerjaan ibu) terhadap kesiapan bersekolah secara keseluruhan independen variabel maupun masing-masing independen variabel.

\section{Metode Penelitian}

Populasi penelitian ini adalah ibu dari siswa sekolah dasar (SD) kelas satu yang sedang menempuh kegiatan pembelajaran di semester satu di wilayah Tangerang Selatan, Depok dan Bandung. Teknik pengambilan sampel yang digunakan dalam penelitian ini bersifat purposive sampling. Pada penelitian ini, subjek penelitian adalah anak usia lima sampai tujuh tahun yang sedang belajar di SD kelas satu. Sampel ataupun responden yang telah ditentukan yaitu ibu dari anak SD kelas satu di semester satu di SDS Kharisma Bangsa Tangerang Selatan, SDS Pribadi Depok, SDS Pribadi Bandung.

Alat ukur kesiapan bersekolah menggunakan EDI (Early Development Instrument), disusun oleh Janus dan Offord (2007). Alat ukur ini mengukur dimensi yang terdapat dalam kesiapan sekolah, yaitu: physical health and well-being, language and cognitive development, social competence, emotional development, yang terdiri dari 101 butir pertanyaan namun disesuaikan menjadi 30 butir item pertanyaan.

Alat ukur yang digunakan dalam dukungan ibu menggunakan teori Epstein (2001) yang berisikan 28 pertanyaan Effective Parent Involvement: Parent and Teacher Perceptions, namun penggunaanya akan diadaptasi dan disesuaikan dengan keperluan penelitian ini, yaitu berdasarkan persepsi ibu.

Alat ukur kelekatan ibu dan anak berdasarkan teori dari Ainsworth (1978), yaitu dengan mengukur dimensi secure attachment, insecure anxious-ambivalent attachment dan insecure anxious-avoidant attachment dan disorganized attachment yang berjumlah 28 item.

Skala yang digunakan menggunakan skala likert 4 poin, yang digunakan menggunakan skala likert 4 point, skala 1 (selalu), 2 (sering), 3 (kadang-kadang), sampai dengan skala 4 (tidak pernah).

\section{Hasil Penelitian}

Pada tabel 4.5 dapat dilihat bahwa diperoleh $R$-square sebesar 0.118 atau $11.8 \%$. Artinya pengaruh proporsi dukungan ibu, kelekatan ibu dan anak (secure attachment, insecure anxiousambivalent attachment, insecure anxious-avoidant attachment, dan disorganized attachment), dan variabel demografi (usia anak, jenis kelamin, urutan kelahiran, dan status pekerjaan ibu) terhadap kesiapan bersekolah sebesar $11.8 \%$, sedangkan $88.2 \%$ sisanya diperngaruhi oleh variabel lain di luar penelitian ini.

Table 4.5

$R$ square

Model Summary

Model R R Square Adjusted R Square Std. Error of the Estimate

\begin{tabular}{lllll}
\hline 1 & $.343^{\mathrm{a}}$ & .118 & .076 & 9.16895
\end{tabular}


a.Predictors: (Constant), pekerjaan ibu, jenis kelamin, disorganized_attachment, dukungan_orangtua, usia masuk sekolah, urutan kelahiran, secure_attachment, insecure_avoidant, insecure_ambivalent

Langkah kedua peneliti menganalisis pengaruh dari keseluruhan variabel terhadap kesiapan bersekolah. Berdasarkan uji F pada tabel 4.6 dapat dilihat bahwa uji F sebesar 2.841 dengan Sig. 004 (sig < 0,05) maka hipotesis nihil yang menyatakan tidak ada pengaruh yang signifikan antara variabel dukungan ibu, kelekatan ibu dan anak (secure attachment, insecure anxious-ambivalent attachment, insecure anxious-avoidant attachment, dan disorganized attachment), dan variabel demografi (usia anak, jenis kelamin, urutan kelahiran, dan status pekerjaan ibu) terhadap kesiapan bersekolah ditolak. Artinya, ada pengaruh yang signifikan secara bersama-sama dari variabel dukungan ibu, kelekatan ibu dan anak (secure attachment, insecure anxious-ambivalent attachment, insecure anxious-avoidant attachment, dan disorganized attachment), dan variabel demografi (usia anak, jenis kelamin, urutan kelahiran, dan status pekerjaan ibu) terhadap kesiapan bersekolah.

\section{Tabel 4.6}

Signifikansi Uji Regresi

\begin{tabular}{lllllll}
\hline Model & & Sum of Squares & df & Mean Square & F & Sig. \\
\hline \multirow{3}{*}{1} & Regression & 2149.4928 & 10 & 238.832 & 2.841 & $.004^{\mathrm{b}}$ \\
& Residual & 16141.3671 & 192 & 84.070 & & \\
& Total & 18290.8599 & 202 & & & \\
\hline
\end{tabular}

a. Dependent Variable: kesiapan_sekolah

b.Predictors: (Constant), pekerjaan ibu, jenis kelamin, disorganized_attachment, dukungan_orangtua, usia masuk sekolah, urutan kelahiran, secure_attachment, insecure_avoidant, insecure_ambivalent

Langkah terakhir, peneliti melihat koefisien regresi dari masing-masing independent variable (IV). Jika sig <0,05 maka koefisien regresi tersebut signifikan yang berarti variabel independen tersebut memiliki pengaruh terhadap kesiapan bersekolah. Adapun besarnya koefisien regresi dari masing-masing IV terhadap kesiapan bersekolah dapat dilihat dari tabel 4.7 


\section{Tabel 4.7}

Koefisien Regresi Independent Variabel (IV) terhadap Dependent Variabel (DV)

\begin{tabular}{llllll}
\hline Model & \multicolumn{2}{l}{$\begin{array}{l}\text { Unstandardized } \\
\text { Coefficients }\end{array}$} & $\begin{array}{l}\text { Standardized } \\
\text { Coefficients }\end{array}$ & T & Sig. \\
& $\mathrm{B}$ & Std. Error & Beta & & \\
\hline (Constant) & 32.317 & 9.066 & & 3.565 & .000 \\
Dukungan ibu & .269 & .070 & .269 & 3.863 & .000 \\
Secure attachment & .080 & .117 & .079 & .680 & .497 \\
Insecure ambivalent & -.081 & .108 & -.084 & -.749 & .455 \\
Insecure Avoidant & .059 & .097 & .059 & .611 & .542 \\
Disorganized Attachment & -.018 & .084 & -.018 & -.212 & .832 \\
Usia Masuk Sekolah & .623 & 1.415 & .031 & .440 & .660 \\
Jenis Kelamin & 3.378 & 1.310 & .177 & 2.578 & .011 \\
Urutan Kelahiran & -.372 & .612 & -.043 & -.608 & .544 \\
Status Pekerjaan Ibu & -.055 & 1.371 & -.003 & -.040 & .968
\end{tabular}

a. Dependent Variable: kesiapan_sekolah

Berdasarkan tabel 4.7 dapat dipaparkan persamaan regresi sebagai berikut: kesiapan bersekolah $=32.317+0.269 *$ dukungan $\mathrm{ibu}+0.080 *$ secure attachment $-0,081 *$ insecure anxious ambivalent attachment $+0,059 *$ insecure anxious-avoidant attachment $-0.018 *$ disorganized attachment $+0,623 *$ usia masuk sekolah $+3,378 *$ jenis kelamin $-0.372 *$ urutan kelahiran $0.055 *$ status pekerjaan ibu + e.

Untuk melihat signifikan atau tidaknya koefisien regresi yang dihasilkan dengan melihat nilai Sig. tabel 4.7 jika sig < 0,05 maka pengaruh koefisien regresi dihasilkan bernilai signifikan terhadap kesiapan bersekolah dan begitupun sebaliknya. Pada tabel 4.7 terdapat dua koefisien regresi yang signifikan, yaitu dukungan ibu 0,000 dan jenis kelamin 0,000. Sedangkan variabel lainnya menghasilkan koefisien regresi yang tidak signifikan. Hal ini berarti dari delapan hipotesis minor hanya dua saja yang signifikan. 


\section{Tabel 4.8}

Proporsi Varian DV yang disebabkan masing-masing IV

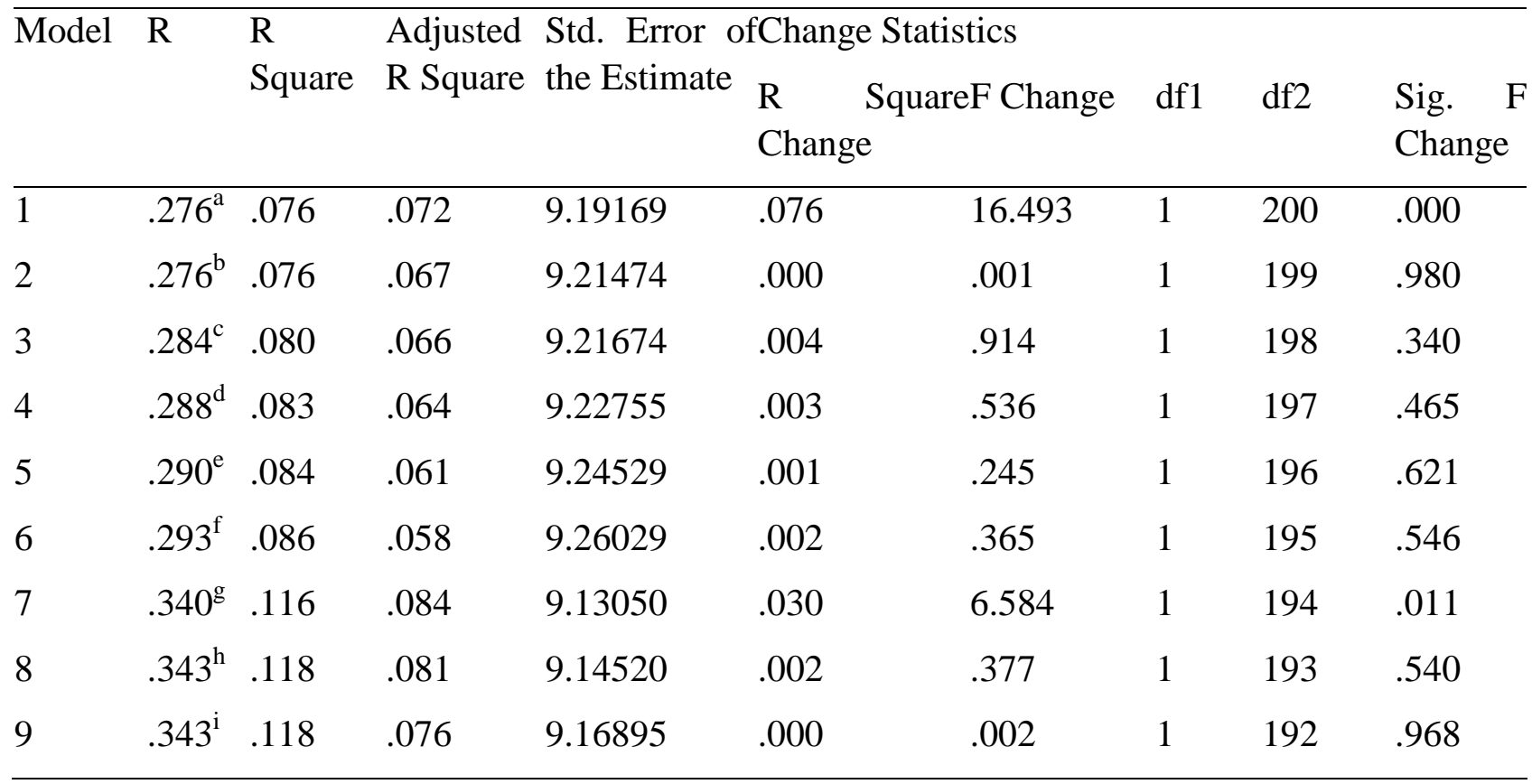

Penjelasan proporsi varian masing-masing kesiapan bersekolah yang dijelaskan masing-masing independent variabel (IV) dari tabel 4.8 adalah sebagai berikut:

a. Variabel dukungan ibu memberikan sumbangan sebesar 0.076 atau $7.6 \%$ dengan Sig. F change $=0.000$, sumbangan tersebut signifikan.

b. Variabel secure attachment memberikan sumbangan sebesar 0.000 atau $0 \%$ dengan Sig. F change $=0.980$, sumbangan tersebut tidak signifikan.

c. Variabel insecure anxious-ambivalent attachment memberikan sumbangan sebesar 0.004 atau $0.4 \%$ dengan Sig. F change $=0.340$, sumbangan tersebut tidak signifikan.

d. Variabel insecure anxious-avoidant attachment memberikan sumbangan sebesar 0.002 atau $0.2 \%$ dengan Sig. F change $=0.465$, sumbangan tersebut tidak signifikan .

e. Variabel disorganized attachment memberikan sumbangan sebesar 0.001 atau $0.1 \%$ dengan Sig. F change 0.621, sumbangan tersebut tidak signifikan.

f. Variabel usia masuk sekolah memberikan sumbangan sebesar 0.002 atau $0.2 \%$ dengan Sig. F change 0.546 , sumbangan tersebut tidak signifikan.

g. Variabel jenis kelamin memberikan sumbangan sebesar 0,030 atau 3\% dengan Sig. F change 0,011, sumbangan tersebut signifikan.

h. Variabel urutan kelahiran memberikan sumbangan sebesar 0.002 atau $0.2 \%$ dengan Sig. F change 0.540 , sumbangan tersebut tidak signifikan.

i. Variabel status pekerjaan ibu memberikan sumbangan sebesar 0.000 atau 0\% dengan Sig. F change 0.968 , sumbangan tersebut tidak signifikan.

Jadi dapat disimpulkan bahwa terdapat dua variabel yang signifikan berdasarkan proporsi variannya, yaitu dukungan ibu dan jenis kelamin, dimana dukungan ibu sebagai variabel yang 
memberikan sumbangan terbesar pada kesiapan bersekolah anak Sekolah Dasar. Selain itu usia enam tahun merupakan rata-rata usia dengan kesiapan sekolah yang tinggi di dalam penelitian ini.

\section{Diskusi}

Berdasarkan hasil penelitian yang telah dilakukan, diketahui bahwa dari sembilan independent variable yang diteliti terdapat dua variabel yang memengaruhi kesiapan bersekolah secara signifikan. Kedua variabel tersebut yaitu dukungan ibu dan jenis kelamin anak.

Berdasarkan kategorisasi dari hasil penelitian ini, kesiapan bersekolah anak SD kelas satu cenderung tinggi, yang artinya banyak anak tersebut yang sudah siap bersekolah. Hasil dari frekuensi dukungan ibu rendah namun hasilnya signifikan menunjukan bahwa dukungan ibu sangat berpengaruh pada kesiapan bersekolah anak. Usia masuk sekolah yang memiliki kesiapan bersekolah tinggi adalah usia enam tahun.

Pada penelitian ini, bentuk dukungan ibu yang dimaksud adalah orang tua secara aktif terlibat dan mendukung kesiapan bersekolah dan prestasi belajar anak. Bentuk dukungan ibu untuk kesiapan bersekolah anak seperti memerhatikan kesehatan anak dengan memberikan bekal yang bernutrisi dan menjaga kesehatan anak. Keterlibatan ibu dalam kegiatan sekolah dengan menjalin komunikasi dengan guru anak, memantau perkembangan anak selama di sekolah kemudian ikut terlibat dengan kegiatan sekolah. Selain itu pendampingan ibu di rumah seperti membantu melatih anak di rumah, memberikan perhatian yang lebih terhadap kekurangan anak, serta melaksanakan aturan yang konsisten dengan sekolah.

Hasil penelitian di atas senada dengan penelitian yang dilakukan oleh Drake (2000), yaitu orang tua berkontribusi secara signifikan terhadap kesiapan bersekolah. Demikian pula dengan penelitian Carter (2002). Selanjutnya, jenis kelamin dalam penelitian ini menunjukkan bahwa anak perempuan lebih siap daripada anak laki-laki. Hasil ini sejalan dengan hasil penelitian yang dilakukan di Amerika Utara dan Eropa dimana anak perempuan lebih siap bersekolah daripada anak laki-laki (Angenent dan de Man, 1989; Janus dan Duku, 2007; Mendez, Mihalas dan Hardesty, 2006).

Variabel yang tidak signifikan dalam penelitian ini, yaitu status pekerjaan ibu yang tidak memengaruhi kesiapan bersekolah anak, hasil tersebut berbeda dengan penelitian yang dilakukan oleh Lombardi dan Coley (2014), mengatakan bahwa ibu bekerja memengaruhi rendahnya kognitif anak. Kelekatan ibu-anak dalam penelitian ini tidak memengaruhi kesiapan bersekolah anak, sama dengan hasil penelitian yang dilakukan oleh oleh Shiller, Izard dan Hembree (1986) tentang kelekatan anak-orang tua yang tidak berhubungan dengan prestasi anak.

Dalam penelitian ini tentu terdapat kekurangan berikut adalah saran untuk penelitian selanjutnya. Sampel penelitian ini menggunakan karakteristik anak yang bersekolah di sekolah-sekolah dengan lingkungan yang sederajat, dan kurikulum yang sama. Saran untuk penelitian selanjutnya untuk mencari sekolah dengan lingkungan dan sosial ekonomi yang berbeda dan lebih bervariasi misalkan, perkotaan-pedesaan, sekolah internasional-sekolah nasional, strata sosial tinggi-strata sosial bawah/sedang serta mencari sekolah dengan peraturan penerimaan murid yang berbeda. Untuk penelitian lebih lanjut dapat diteliti tentang hubungan antara dukungan ayah dan kelekatan ayah-anak terhadap kesiapan bersekolah anak.

Sedangkan secara praktis dijelaskan berikut ini. Pada penelitian ini dihasilkan bahwa dukungan ibu memengaruhi kesiapan bersekolah anak. Disarankan untuk para orang tua agar memberikan dukungannya, baik berupa dukungan dalam perkembangan fisiknya maupun perkembangan kognitif, bahasa dan sosial emosional anak. Dukungan dalam menciptakan lingkungan rumah yang 
kondusif untuk perkembangan anak, membangun komunikasi dan terlibat dengan kegiatan sekolah anak serta membantu anak belajar di rumah. Mempertimbangkan kesimpulan dalam penelitian ini yang menunjukkan jenis kelamin memengaruhi kesiapan bersekolah anak, dimana anak perempuan lebih siap daripada anak laki-laki. Pada anak laki-laki untuk diberikan dukungan lebih intensif, misalkan memberikan bimbingan belajar di rumah, memberikan perhatian lebih pada perkembangan emosi dan sosial anak laki-laki serta perkembangan bahasanya.

Hasil penelitian dari dukungan ibu yang berbanding terbalik dengan kelekatan ibu-anak dan status pekerjaan ibu, memperlihatkan bahwa perhatian dan dukungan ibu sangat berperan walaupun ibu tersebut bekerja di luar rumah. Disarankan agar orang tua atau ibu memberikan waktu khusus untuk memberikan dukungan dan perhatian terhadap perkembangan anak. Peneliti dapat melakukan parenting kepada orang tua murid SD maupun TK tentang pentingnya kesiapan bersekolah, yang isinya meliputi perkembangan fisik, kognitif, bahasa, sosial dan emosional anak.

\section{Daftar Pustaka}

Ainsworth, M.D., Blehar, M.C., Waters, E., Wall, S. (1978). Patterns of attachment: A psychological study of the strange situation. Oxford, England: Lawrence Erlbaum.

Angenent, H., de Man AF. (1989). Intelligence, gender, social maturity and school readiness in dutch first graders. Social Behaviour and Personality. 17: 205-209.

Bowlby, J.(1988). Attachment and loss: Vol I Attachment. New York: Basic Books.

Carter, M. (2002). The impact of parent and family involvement of student outcomes: An annotated bibliography of research from the past decade. CADRE. 2002-00-00.

Chiccetti, D., \& Carlson. (1989). Child's maltreatment : Theory and research on the causes and concequences of child abuse and neglect. UK : Cambridge University Press.

Cole, P. (2006). All children ready for school: Heath and physical well being. Early Childhood Center. IN 47408-2696.

Compton, M. (2004). Parent involvement in pre-kindergarten and the effects on student achievement. Thesis, Kansas, US: Wichita State University.

Connel, C.M., \& Prinz, R.J. (2002). The impact of childcare and parent-child interaction on school readiness and social skills development for low-income American children. Journal of School Psychology. 40 (2) pp. 177-193.

Cross, A.F. \& Powers, M.C. (2011). A working paper: New information about school readiness. Bloomington: Indiana University.

DeKlyen, M., Biernbaum, M. A., Speltz, M. L., \& Greenberg, M. T. (1998). Fathers and preschool behavior problems. Developmental Psychology, 34(2), 264-275.

DeMulder, E. K., Denham, S., Schmidt, M., \& Mitchell, J. (2000). Q-sort assessment of attachment security during the preschool years: Links from home to school. Developmental Psychology, 36(2), 274-282.

Dobbs, J., Doctoroff, G. L., Fisher, P. H., \& Arnold, D. H. (2006). The association between preschool children's socio-emotional functioning and their mathematical skills. Journal of Applied Developmental Psychology, 27(2), 97-108.

Duncan, G.J., Claessens.A., Huston, A.C., Pagani,L.S., Engel, M., Sexton,H., Dosett, C.J., Magnuson, K., Klebanov,P., Feinstein, L., Brooks-Gunn, J., Duckworth, K. \& Japel, C. (2007). School raediness and later achievement. Journal of Developmental Psychology, 43, 1428-1446.

Epstein, J.L. (2001). School, family, and community partnerships: Preparing educators and improving schools. New York: Corwinpress. ISBN-0-7619-7666-3. 
Graue,M.E. (1992). Social interpretation of readiness for kindergarten. Early Childhood Reseach Quarterly. Doi: 10.1016/0885-2006(92)90006-K.

Gredler, G.R. (1992). School readiness: Assesment and educational issues. US:. Willey Press. ISBN-0-88422-112-1.

He Ye. (2016). Parental involvement in school readiness programs. Higher Education of Social Science. Doi: 10.3968/8708.

Huffman, L.C., Mehlinger,S.L., \& Kerivan, A.S. (2000). Risk Factors for Academic and Behavioral Problems at The Beginning of School. Chapel Hill. North Carolina: University of North Carolina.

Jacobsen, T., \& Hofmann, V. (1997). Children's attachment representations: Longitudinal relations to school behavior and academic competency in middle chilhood and adolescence. American Psychological Assosiation.

Janus, M. \& Offord, D.R. (2007). Development and psychometric properties of the early development instrument (edi): a measure of children's school readiness. Canadian Journal of Behavioural Science, 39, 1-22.

Janus, M. \& Duku, E. (2007). The school entry gap: socioeconomic, family, and health factors associated with children's school readiness to learn. Early Education and Developent. 18: 375-403.

Krause, K. L., Bochner, S., Duchesne, S. \& McMaugh, A.(2010). Educational psychology (for learning and teaching). Australia: Cencage Learning Australia.

Lara-Cinisomo, Sandraluz. (2004). Are L.A's children ready for school?. California: Rand Corporation.

Lombardi, Caitlin M, \& Coley, Rebekah L. (2014). Early Maternal Employment and Children's School Readiness in Contemporary Families. Developmental Psychology.

Main, M. \& Solomon, J. (1986). Discovery of a new, insecure-disorganized/disoriented attachment pattern. US : Ablex Publishing.

Mendez, L., Mihalas, S., Hardesty, R. (2006). Gender differences in academic development and performances. Washington DC: NAEYC.

Piaget, J. (1951). Psychology of intelligence. London: Routledge and Kegan Paul.

Shala, Merita. (2013). The Impact of Preschool Social-Emotional Development on Academic Success of Elementary School Students. Scientific Research.

Shiller, V.M., Izzard, C.E., Hembree, E.A. (1986). Pattern of emotion expression during separation in the strange situation. Developmental Psychology; 22:378-383.

United Nations Children's Fund. (2012). School readiness and transitions. New York : UNICEF

United Nations Children's Fund. (2011). School readiness : Conceptual Framework. New York : UNICEF

Van IJzendoorn, M. H., Dijkstra, J., \& Bus, A. G. (1995). Attachment, intelligence, and language: A meta-analysis. Social Development, 4(2), 115-128. 